\title{
Thermal-hydraulic optimisation of the DEMO divertor cassette body cooling circuit equipped with a liner
}

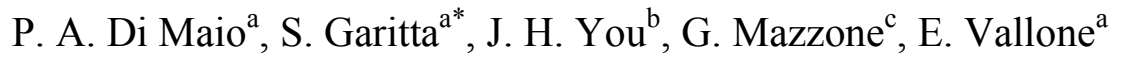 \\ ${ }^{a}$ University of Palermo, Viale delle Scienze, Edificio 6, 90128 Palermo, Italy \\ ${ }^{b}$ Max Planck Institute of Plasma Physics (E2M), Boltzmann Str.2, 85748 Garching, Germany \\ ${ }^{c}$ Department of Fusion and Technology for Nuclear Safety and Security, ENEA C.R. Frascati, via E. Fermi 45, 00044 \\ Frascati (Roma), Italy
}

Within the framework of the Work Package DIV 1 - "Divertor Cassette Design and Integration" of the EUROfusion action, a research campaign has been jointly carried out by University of Palermo and ENEA to investigate the thermal-hydraulic performances of the DEMO divertor cassette cooling system. The research activity has been focussed onto the most recent design of the Cassette Body (CB) cooling circuit equipped with a Liner, whose main function is to protect the underlying vacuum pump hole from the radiation arising from the plasma. The research campaign has been carried out following a theoretical-computational approach based on the Finite Volume Method and adopting the commercial Computational Fluid-Dynamic code ANSYS-CFX.

The CB thermal-hydraulic performances have been assessed in terms of coolant and structure temperature, coolant overall pressure drop, flow velocity distribution and mass flow rate fed to the Liner cooling circuit, mainly in order to check coolant aptitude to provide a uniform and effective cooling to both CB and Liner structures.

The outcomes of the study have shown some major criticalities, mainly in terms of water coolant vaporization as well as non-symmetric coolant distribution between the two Liner inlets. As a consequence, the following potential solutions have been successfully explored in order to allow the CB to safely operate while complying with its design constraints:

- revising the $\mathrm{CB}$ design layout in order to increase the coolant mass flow rate fed to Liner;

- increasing coolant inlet pressure to rise water saturation temperature and, hence, its margin against vaporization;

- increasing coolant mass flow rate to reduce its overall thermal rise.

The main results and the achieved optimized model are herewith described and critically discussed.

Keywords: DEMO, divertor, cassette body, CFD analysis, thermofluid-dynamics.

\section{Introduction}

The European Fusion Development Agreement roadmap was elaborated to pursue fusion as a sustainable, secure and commercial energy source [1]. In this framework, the divertor is a fundamental component of fusion power plants, being primarily responsible for power exhaust and impurity removal via guided plasma.

As a consequence, the divertor has to withstand very high heat loads, mainly due to radiative and charged particle fluxes arising from the plasma (up to 20 $\mathrm{MW} / \mathrm{m}^{2}$ ), while experiencing an intense nuclear heat power deposition, which could jeopardize its structure and limit its lifetime. Therefore, attention has to be paid to the thermal-hydraulic design of its cooling system, in order to ensure a uniform and proper cooling, without an unduly high pressure drop.

Within the framework of the Work Package DIV 1 "Divertor Cassette Design and Integration" of the EUROfusion action [2,3] and in line with previous activities [4, 5], in 2017 a research campaign has been jointly carried out by University of Palermo and ENEA to theoretically assess the steady state thermal-hydraulic performances of the DEMO divertor Cassette Body (CB) cooling system.
A theoretical-numerical approach based on the Finite Volume Method has been followed adopting the commercial Computational Fluid-Dynamic (CFD) code ANSYS CFX v.16.2, previously used in similar studies to evaluate concentrated hydraulic resistances to be employed in system codes [6-8].

During the second half of 2017, CFD analyses have been carried out to investigate the steady state thermalhydraulic performances of the latest water-cooled $\mathrm{CB}$ design equipped with a shielding structure called Liner. In addition, the aptitude of the $\mathrm{CB}$ cooling circuit to provide a uniform and effective cooling to both $\mathrm{CB}$ and Liner structures has been assessed and potential solutions devoted to its improvement have been investigated. The assumptions relevant to these thermalhydraulic analyses are herein reported and critically discussed, together with the main results obtained.

\section{Cassette body thermal-hydraulic analysis}

According to its 2016 design, DEMO divertor is articulated in 54 toroidal cassettes, each composed of two Plasma Facing Components (PFCs), namely an inner and an outer vertical target, and a cassette body. In October 2017, a new divertor CB concept has been devised, mainly characterised by the presence of a Liner (Fig. 1) $[9,10]$. 


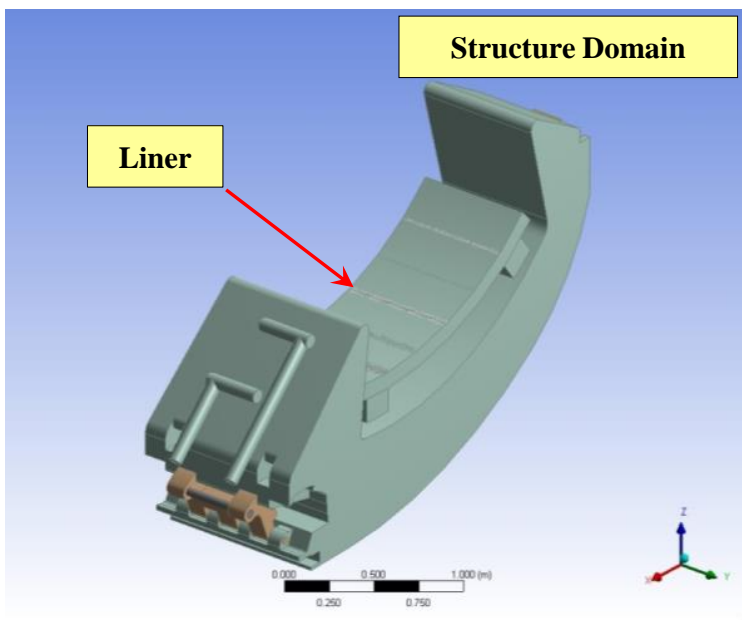

Fig. 1. CB with Liner (October 2017 design).

The $\mathrm{CB}$ is endowed with an active cooling circuit relying on the use of subcooled pressurized water at the inlet pressure and temperature of $3.5 \mathrm{MPa}$ and $180{ }^{\circ} \mathrm{C}$, respectively, flowing with a thermal rise of $30{ }^{\circ} \mathrm{C}$.

\section{CB with Liner Cooling Circuit CFD Analysis}

The hydraulic behaviour of the relevant cooling circuit has been assessed by means of a dedicated CFD analysis, along with its aptitude to provide an effective cooling to both $\mathrm{CB}$ and Liner structures.

The considered coolant operative conditions are reported in Table 1.

The selected mesh parameters are reported in Table 2 while the main assumptions adopted, models and boundary conditions are listed in Table 3 .

The total coolant pressure drops across the main sections of the circuit (Fig. 2) are summarised in Table 4.

Table 1. Summary of CB coolant operative conditions.

\begin{tabular}{lc}
\hline & Conditions \\
\hline Inlet Pressure [MPa] & 3.5 \\
Inlet Temperature $\left[{ }^{\circ} \mathbf{C}\right]$ & 180 \\
$\Delta \mathrm{T}\left[{ }^{\circ} \mathbf{C}\right]$ & 30 \\
Removed Power $(\mathbf{5 4}$ Cassette) $[\mathrm{MW}]$ & 115.2 \\
G per Cassette $[\mathbf{k g} / \mathbf{s}]$ & 15.94 \\
\hline
\end{tabular}

Table 2. Summary of the main mesh parameters.

\begin{tabular}{lc}
\hline Nodes & $2.12 \cdot 10^{+7}$ \\
Elements & $5.08 \cdot 10^{+7}$ \\
Inflation layers number & 10 \\
First layer thickness $[\boldsymbol{\mu m}]$ - Liner & 20 \\
First layer thickness $[\boldsymbol{\mu m}]$ - CB & 200 \\
Layers growth rate & 1.4 \\
Typical element size $[\mathrm{m}]$ & $5.16 \cdot 10^{-3}$ \\
\hline
\end{tabular}

Table 3. Summary of CFD analysis setup.

\begin{tabular}{lc}
\hline Analysis type & $\begin{array}{c}\text { Steady state isothermal } \\
\text { Material library }\end{array}$ \\
Temperature & $195{ }^{\circ} \mathrm{C}$ \\
Turbulence model & $\mathrm{k}-\varepsilon$ \\
Boundary layer modelling & Scalable wall functions \\
Absolute wall roughness & $15 \mu \mathrm{m}$ \\
Inlet BC & Static pressure $=3.5 \mathrm{MPa}$ \\
Outlet BC & Mass flow rate $=15.94 \mathrm{~kg} / \mathrm{s}$ \\
Surface with $\mathbf{y}^{+}<\mathbf{1 3 0}[\mathbf{\%}]$ & 96 \\
\hline
\end{tabular}

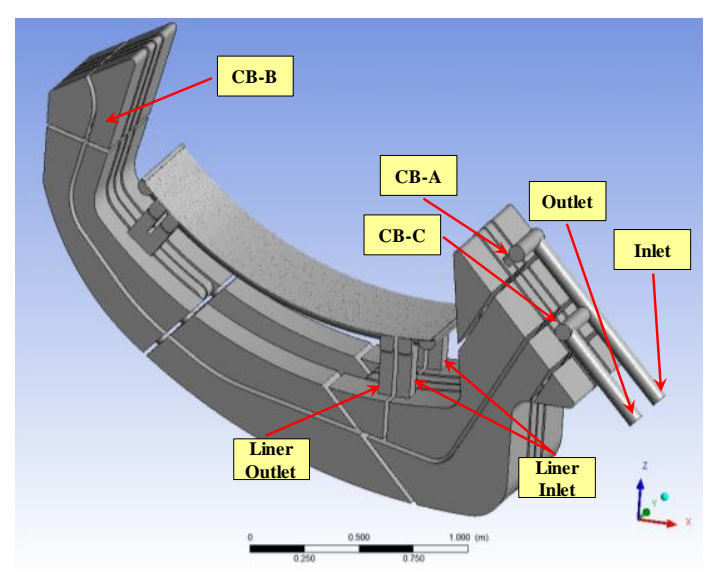

Fig. 2. CB with Liner cooling circuit main sections.

Table 4. CB cooling circuit total pressure drop distribution.

\begin{tabular}{lcc}
\hline Sections & Pressure points & $\Delta \mathbf{p}[\mathbf{M P a}]$ \\
\hline Inlet Manifold & Inlet - CB-A & 0.0201 \\
Upper cassette 1 & CB-A - Liner Inlet & 0.0115 \\
Liner & Liner Inlet - Liner Outlet & 0.0055 \\
Upper cassette 2 & Liner Outlet - CB-B & 0.0184 \\
Lower cassette & CB-B - CB-C & 0.0305 \\
Outlet manifold & CB-C - Outlet & 0.0183 \\
Cassette total & Inlet - Outlet & $\mathbf{0 . 1 0 4 3}$ \\
\hline
\end{tabular}

Fig. 3 illustrates the flow path the coolant follows. Specifically, the green and yellow arrows point out the inlet/outlet section of the Liner, while the red arrows are related to the flow that bypasses the Liner.

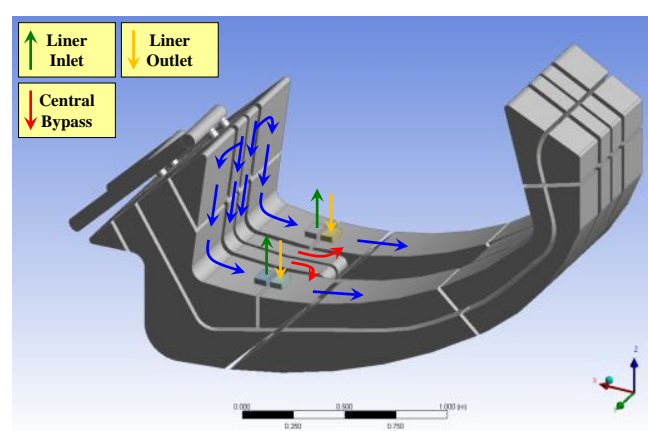

Fig. 3. CB with Liner coolant flow path (section). 
In particular, as shown in Table 5, only a small fraction $(\sim 10 \%)$ of the overall mass flow rate actually cools the Liner structure.

Table 5. CB with Liner mass flow rates distribution.

\begin{tabular}{lcc}
\hline Sections & $\mathbf{G}[\mathbf{k g} / \mathbf{s}]$ & $\mathbf{G} / \mathbf{G}_{\text {Tot }}$ \\
\hline Liner & 1.69 & $10.6 \%$ \\
Central bypass & 14.25 & $89.4 \%$ \\
Cassette total & 15.94 & - \\
\hline
\end{tabular}

Moreover, a deeply non-symmetric mass flow rate distribution is predicted between the two Liner inlets, since about $1.1 \mathrm{~kg} / \mathrm{s}$ of coolant flows through one of them, leaving the other one with only about $35 \%$ of the Liner mass flow rate. This asymmetry is due to the $\mathrm{CB}$ inlet manifold configuration and it might induce potentially severe thermofluid-dynamic instabilities, to be further investigated if deemed necessary.

\section{CB with Liner Coolant Thermal Study}

In order to investigate the aptitude of the CB cooling circuit to provide a uniform and effective cooling to both $\mathrm{CB}$ and Liner structures, its coolant thermal behaviour has been assessed on the basis of the CB CFD analysis results described in the previous paragraph. A theoretical approach based on the Lumped Parameter Method has been followed and the 1D model of the CB cooling circuit reported in Fig. 4 has been adopted for calculations. A steady state, incompressible and quasiisobaric flow has been assumed.

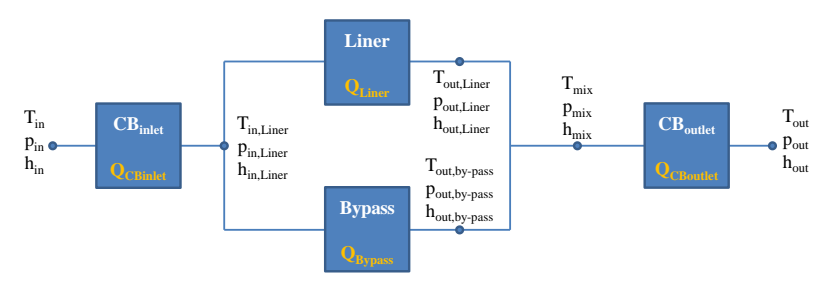

Fig. 4. Representation of the CB cooling circuit 1D model.

The total heat power deposited within the Liner $\left(\mathrm{Q}_{\mathrm{Liner}}\right)$ has been evaluated as follows:

$$
\mathrm{Q}_{\text {Liner }}=\mathrm{Q}_{\text {Liner,distr }}+\mathrm{q}^{\prime \prime} \cdot \mathrm{A}_{\text {Liner }}
$$

where:

- $\mathrm{Q}_{\text {Liner,distr }}$ represents the nuclear-deposited heat power within the Liner structure and it has been evaluated to be $0.72 \mathrm{MW}$ by integrating over the Liner domain the nuclear heating distribution calculated by ENEA Frascati [3], properly scaled so to save the overall 115.2 MW (Table 1);

- $\mathrm{q}^{\prime \prime} \cdot \mathrm{A}_{\mathrm{Liner}}$ represents the deposited heat power due to the heat flux onto the Liner plasma facing surface.
$\mathrm{Q}_{\mathrm{CBinlet}}, \mathrm{Q}_{\mathrm{CBoutlet}}$ and $\mathrm{Q}_{\text {Bypass }}$ have been evaluated by means of a CFD analysis previously carried out for the CB cooling circuit without the Liner [4].

Even considering the ideal case of a negligible heat flux acting onto the Liner plasma facing surface $\left(\mathrm{q}^{\prime \prime} \approx 0\right)$, it can be shown that water coolant is predicted to vaporize within the Liner.

This preliminary conclusion poses the need for the mandatory improvement of the CB coolant thermalhydraulic performances. The following potential solutions might be considered:

- increasing coolant inlet pressure to rise water saturation temperature $\left(\mathrm{T}_{\mathrm{sat}}\right)$ and, hence, its margin against vaporization;

- increasing coolant inlet temperature to enhance the coolant specific heat capacity $\left(\mathrm{c}_{\mathrm{p}}\right)$ and, hence, reduce its overall thermal rise $(\Delta \mathrm{T})$;

- increasing coolant mass flow rate $(G)$ to reduce its $\Delta \mathrm{T}$ (hence incurring in a pressure drop increase roughly proportional to $\mathrm{G}^{2}$ );

- revising $\mathrm{CB}$ design layout in order to:

increase coolant mass flow rate to the Liner (reducing bypass flow area);

$>$ reduce nuclear-deposited heat power (reducing Liner thickness).

Within the framework of the research campaign, attention has been focussed on the revision of the $\mathrm{CB}$ design layout, aimed at increasing the coolant mass flow rate fed to the Liner.

To this purpose, the reduction of the central bypass flow area (Fig. 5) has been considered in order to increase the hydraulic resistance against coolant flow towards $\mathrm{CB}$ legs and, hence, ease coolant routing to the Liner.

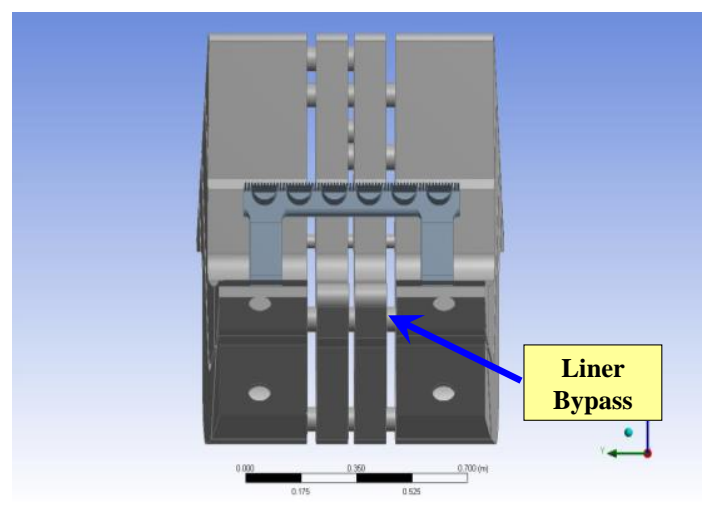

Fig. 5. Liner bypass.

The effectiveness of this solution has been extensively investigated by means of a CFD parametric analysis intended to assess the mass flow rate distribution within the $\mathrm{CB}$ cooling circuit and the corresponding total pressure drop according to the 
variation of the flow area restriction parameter $(\xi)$, defined as follows:

$$
\xi=\mathrm{A} / \mathrm{A}_{0}
$$

where $\mathrm{A}$ is the modified value of the central bypass flow area and $\mathrm{A}_{0}$ its reference, original value.

The obtained results are summarised in Fig.s 6 and 7, focussing the attention on how mass flow rates distribution and pressure drops change thanks to the decrease of the central bypass flow area.

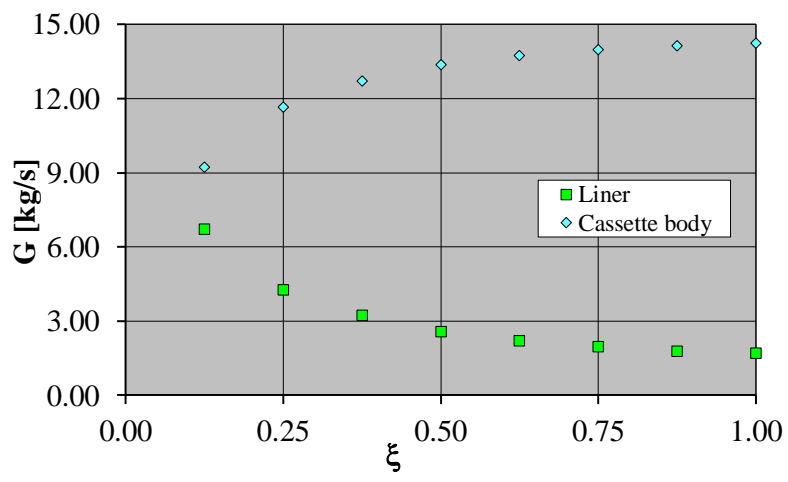

Fig. 6. Mass flow rates distribution with different values of $\xi$.

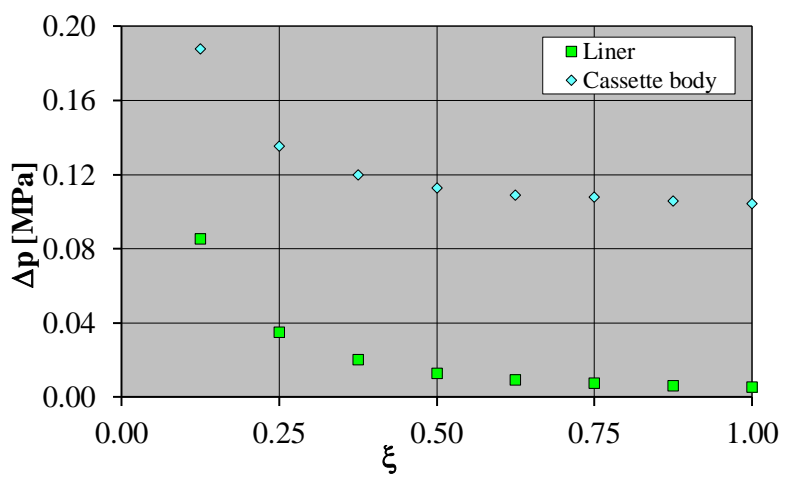

Fig. 7. Pressure drops with different values of $\xi$.

According to the results of the previous CFD parametric analysis and adopting the 1D model of the CB cooling circuit previously set-up, a set of thermalhydraulic studies has been performed for each revised configuration of the $\mathrm{CB}$ cooling circuit, considering different possible values of the heat flux onto the Liner plasma facing surface.

For each configuration and heat flux value, the coolant temperature predicted at the Liner outlet has been compared to the corresponding saturation value, in order to check whether vaporization occurs or not and, hence, to assess whether the configuration may be deemed as viable.

A 3D operative map has been obtained, representing the coolant margin against saturation at the Liner outlet $\left(\Delta \mathrm{T}_{\text {sat,liner }}\right)$ as a function of the configuration $(\xi)$ and the heat flux assumed onto the Liner plasma facing surface (q"). This map is illustrated in a detailed view in Fig. 8 for heat fluxes between 0 and $1 \mathrm{MW} / \mathrm{m}^{2}$.

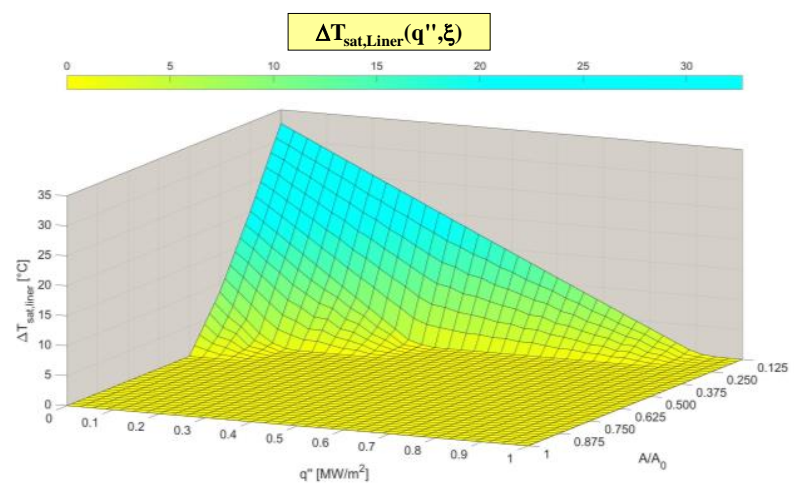

Fig. 8. Coolant margin against saturation at the Liner outlet.

From the analysis of the results it might be argued that the "most promising" CB configuration is the one characterized by $\xi=0.125$, that results in a coolant mass flow rate in the Liner of $6.71 \mathrm{~kg} / \mathrm{s}$. In particular, assuming a minimum $\Delta \mathrm{T}_{\text {sat }}=10{ }^{\circ} \mathrm{C}$, the maximum tolerable $\mathrm{q}^{\prime \prime}$ amounts to $0.6 \mathrm{MW} / \mathrm{m}^{2}$. To raise this maximum value, further solutions have to be considered.

\section{Conclusions}

Within the framework of the activities foreseen in the Work Package DIV 1 - "Divertor Cassette Design and Integration" of the EUROfusion action, a research campaign has been carried out at the University of Palermo, in cooperation with ENEA, to investigate the steady state thermal-hydraulic performances of the divertor CB cooling circuit, focussing the attention on the latest concept of its water cooled option, characterised by the presence of a Liner.

The hydraulic behaviour of its cooling circuit has been assessed by means of a dedicated CFD analysis, that has shown not only that only a small percentage of the overall mass flow rate is routed towards the Liner $(\sim 10 \%)$, but also that a deeply non-symmetric mass flow rate distribution is predicted between the two Liner inlets, due to the $\mathrm{CB}$ inlet manifold configuration. Those characteristics might induce potentially severe thermofluid-dynamic instabilities, hence they need to be adequately addressed.

As a result, a theoretical approach based on a lumped parameter 1D model has been followed in order to assess the coolant thermal behaviour as well as its effectiveness at cooling both $\mathrm{CB}$ and Liner structures. This study has shown that, even considering the ideal case of a negligible heat flux onto the Liner plasma facing surface, water coolant is predicted to vaporize within the Liner. In order to avoid vaporization occurrence, attention has been focussed on the $\mathrm{CB}$ design revision due to the reduction of the central bypass flow area. A parametric analysis has indicated that the "most promising" CB configuration is the one characterized by a flow area 
reduction parameter of 0.125 , that is able to withstand a maximum $\mathrm{q}^{\prime \prime}$ of $0.6 \mathrm{MW} / \mathrm{m}^{2}$, with a minimum margin against saturation of $10^{\circ} \mathrm{C}$.

\section{Acknowledgments}

This work has been carried out within the framework of the EUROfusion Consortium and has received funding from the Euratom research and training programme 2014-2018 under grant agreement No 633053. The views and opinions expressed herein do not necessarily reflect those of the European Commission.

\section{References}

[1] F. Romanelli et al., Fusion Electricity - A Roadmap to the Realisation of Fusion Energy, European Fusion Development Agreement (EFDA), 2012, ISBN 978-3-00040720-8T.

[2] J.H. You et al., Conceptual design studies for the European DEMO divertor: Rationale and first results, Fusion Eng. Des. 109-111 (2016) 1598-1603, http://dx.doi.org/10.1016/j.fusengdes.2015.11.012.

[3] J.H. You, et al., Progress in the initial design activities for the European DEMO divertor: Subproject "Cassette", Fusion Eng. Des. 124 (2017) 364-370, https://doi.org/10.1016/j.fusengdes.2017.03.018.

[4] P.A. Di Maio, S. Garitta, J. H. You, G. Mazzone, M. Marino, E. Vallone, Computational thermofluid-dynamic analysis of DEMO divertor cassette body cooling circuit, Fusion Eng. Des. $136 \quad$ (2018) 1588-1592, https://doi.org/10.1016/j.fusengdes.2018.05.063.

[5] P.A. Di Maio, S. Garitta, J. H. You, G. Mazzone, E. Vallone, Analysis of steady state thermal-hydraulic behaviour of the DEMO divertor cassette body cooling circuit, Fusion Eng. Des. 124 (2017) 437-441, http://dx.doi.org/10.1016/j.fusengdes.2017.02.012.

[6] P.A. Di Maio et al., Analysis of the steady state hydraulic behaviour of the ITER blanket cooling system, Fusion $\begin{array}{llll}\text { Eng. Des. } & 98-99 & \text { (2015) 1470-1473, }\end{array}$ http://dx.doi.org/10.1016/j.fusengdes.2015.05.070.

[7] P.A. Di Maio et al., Numerical simulation of the transient thermal-hydraulic behaviour of the ITER blanket cooling system under the draining operational procedure, Fusion Eng. Des. 98-99 (2015) 1664-1667, http://dx.doi.org/10.1016/j.fusengdes.2015.01.024.

[8] P.A. Di Maio et al., On the hydraulic behaviour of ITER Shield Blocks \#14 and \#08. Computational analysis and comparison with experimental tests, Fusion Eng. Des. 109-111 30-36, http://dx.doi.org/10.1016/j.fusengdes.2016.03.060.

[9] Divertor_CAD_Model_2017, EFDA_D_2MVPNG v1.0.

[10] WPDIV-1-T004 - D005 Development of the CAD model of the Divertor system 2017, EFDA_D_2N6GVQ v1.0. 